\title{
Facilitating Classroom Discussion In Mathematics Instruction To Promote Students' Understanding
}

\author{
${ }^{1}$ Rini Setianingsih*, ${ }^{2}$ Cholis Sa'dijah, ${ }^{3}$ Abdur Rahman As'ari, ${ }^{4}$ Makbul Muksar \\ ${ }^{1}$ Department of Mathematics, Universitas Negeri Surabaya \\ 2,3,4 Pascasarjana Universitas Negeri Malang \\ ${ }^{1,}$ Gedung C8 Kampus Unesa, Jl. Ketintang, Surabaya, Indonesia \\ ${ }^{2,3,4}$ Gedung H3 Kampus Universitas Negeri Malang, Jl. Semarang no. 5 Malang, Indonesia
}

email: rinisetianingsih@unesa.ac.id

\begin{abstract}
This paper presents findings of a qualitative study on efforts to engage elementary school students in small-group and whole-class discussions as part of the process of learning mathematics. Characteristics of the process of facilitating small-group and whole-class discussion are examined, as well as the obstacles and supports. The subjects of this study are 21 fifth-grade students who learn mathematics in small groups and whole-class discussion. The data were collected through classroom observations which were videotaped, while field notes were also taken. The data analysis revealed that students engaged in productive interaction and inquiry while they were learning mathematics in small groups or in whole class setting. This is consistent with the principles of mathematics learning, which gives students wide opportunities to construct mathematical knowledge through individual learning, learning in small groups as well as learning in whole class settings. It also means that by participating in interactive learning, the students are habitually engaged in productive interactions and high level of mathematical thinking. Besides, analysis of the setting suggests that features of the process of facilitating classroom discussion include (a) developing opinions and motivation for discussion, (b) structuring the physical space of the classroom, (c) bringing students' ideas to the forefront of discussion, (d) creating reasons for listening, (e) encouraging students to question and respond to each other, and (f) creating a need for consensus or meaning negotiation. Analysis results also suggest that teachers who implement classroom discussion as a model for learning mathematics struggle with the available time and the curricular constraints and target, as well as student expectations.
\end{abstract}

Keywords- classroom discussion, mathematics instruction, students' understanding.

\section{INTRODUCTION}

Curriculum 2013 which is better known as 'K-13,' has been implemented in Indonesia since 2013. It places a strong emphasis on meaningful process of learning. Consequently, students are expected to be able to construct viable arguments and express their opinion as well as critique the reasoning of others. However, many research results indicate that most mathematics classrooms are still characterized by traditional approaches that endorse the position of mathematics as a kind of received knowledge and the teacher as sole validator of students' contributions [1]. While research shows that classroom discussion can be fertile ground for higher-order mathematical thinking [2], the fast pace with which it is usually associated means that there is little scope for students to make comments and build on each other's mathematical ideas [3]. One consequence of this is that students become disengaged from the subject, perceiving it to be one in which they have little opportunity for participation [1]. However, the orchestration of inquiry-based discussion in mathematics is challenging for teachers. There are two key tensions whereby teachers, on the one hand, are expected to encourage students to share ideas and, on the other, have to ensure that the lesson is mathematically productive [4], [5].

In this study, the researchers considered facilitating discussion to be part of a model of teaching mathematics suggested by Simon [6]. In mathematics classroom, meaningful collaboration relies on purposeful instructional moves from the teacher, as well as a clear understanding of the lesson materials that are placed on students. It means that a teacher should prepare the learning materials properly, and form the small group purposively in order to promote students' discussion that goes together with learning. It often happens that, if group members are not heterogeneous or students are not in their zone of proximal development, the students' collaboration will not work optimally [7]. Therefore, in this study the researcher formed groups of students heterogeneously, and uncovered the actual zone or actual development level of students before collecting the data.

Consistent with a view of mathematics as a socially and culturally situated activity, the point of reference in mathematics instruction is the classroom mathematical practice, a perspective that has been described by Cobb [8] as emergent. This perspective implies that teaching must be improvisational and 'that the most effective learning results when the classroom proceeds in an open, improvisational fashion, as children are allowed to experiment, interact, and participate in the collaborative construction of their own knowledge.' [9]. 
The use of small group work in mathematics classes has both academic and social benefits to students [10], [11], [12]. Although there are many ways that group work can and has been used in mathematics classrooms, one very typical way that some teachers utilize this instructional practice is for students to work on a rich and open-ended task in small groups, often for a substantial period of time within a single lesson. Despite its promise, the use of group work poses particular instructional challenges. For example, (a) Students may not work cooperatively; (b) Academically heterogeneous groups may be difficult to manage; and (c) The teacher's role in monitoring and supervising group work may be confusing and uncomfortable. Furthermore, (d) The teacher must be mindful of the 'group-worthiness' of the task assigned [11], (e) Create classroom norms to facilitate positive group functioning, and ensure that classroom management is kept under control while monitoring accountability and participation of all members of each group.

Martin, Towers and Pirie [14] used the improvisational lens to analyze collective mathematical understanding. They describe collective mathematical understanding as the kind of learning and understandings that occur when a group of any size work together on a mathematical activity. Central to their analysis is the idea of co-acting which they define as, "...a process through which mathematical ideas and actions, initially stemming from an individual learner, become taken up, built on, developed, reworked, and elaborated by others, and thus emerge as shared understandings for and across the group, rather than remaining located within any one individual." [14]. They make a distinction between co-actions and interactions. While in interactions there is an emphasis on reciprocity and mutuality, co-actions concern actions that are dependent and contingent upon the actions of other members of the group. [14]. Through this co-acting, an understanding emerges that is the property of the group rather than any individual. It is not that all individuals bring the same understandings to the scene but rather that individual contributions will result in something greater than the sum of the parts.

According to Martin and Towers [15], '(in) mathematics, 'better' is likely to be defined as a mathematical idea, meriting the attention of the group, which appears to advance them towards the solution to the problem.' Although much of the work done by Martin et al. concerns small groups there is evidence that the metaphor is also applicable to whole class discussion [16]. It is suggested that, in order to achieve a satisfactory balance between process and content, the teacher engages in filtering by which is meant a narrowing of ideas generated by students so that there is a focus on mathematical content. [4].

This article will describe the process of a class teacher in using classroom discussion, implementing, and reflecting on instruction during two months of data collecting. The researchers worked with twenty one grade fifth students, at an elementary school owned by Unesa Foundation. The researchers gathered data to answer the following questions:

(a) What are the features of the process of facilitating classroom discussions in elementary mathematics classrooms?

(b) What are the obstacles encountered by the teacher as she attempts to facilitate classroom discussion?

(c) What supports the teacher in her efforts to facilitate classroom discussion?

Cobb and Bauersfeld [17] identify two general theoretical positions regarding the relationship between individual and social processes and learning, both of which are significant for this study. The first position involves the treatment of learning as an individual constructive process. The second position involves consideration of learning as acculturation into social practices and traditions. Traditionally, doing mathematics in school has meant following a set of rules as stated by the teacher and knowledge has been determined by one's ability to remember and apply these rules [18]. Teaching involved showing and telling, and mathematical content was broken up into smaller and smaller pieces until each piece could be shown to students during a typical class period. Underlying this way of thinking about mathematics teaching and learning is the view of knowledge development as the transmission of information from the teacher who knows to the students who do not know [19]. This is called the "banking concept of education," [20] described how teachers attempt to "deposit" bits of information into students for them to "receive" and "store". The banking, or transmission, model of teaching and learning rests on an understanding of knowledge as a set of ideas separate from human interpretation, and students as passive receptacles capable of being filled with these ideas.

Many educators have rejected this view of teaching and learning in favor of one based on student action and interpretation. Radical constructivists call into question the notion of a body of knowledge independent of knowers and capable of being transmitted to passive learners. They "give up the requirement that knowledge represents an independent world, and admit instead that knowledge represents something that is far more important to us, namely what we can $d o$ in our experiential world" [21]. Rooted in the work of Piaget, radical constructivism holds that knowledge is not passively received but rather actively constructed and interpreted by learners as they try to make sense of their experiences.

For Piaget, the building of conceptual structures is an equilibrium process in which the individual incorporates new ideas into existing cognitive schemas through assimilation and accommodation. Assimilation involves the incorporation of new information into existing schemas, while accommodation involves the restructuring of schemas to make sense of new information. Assimilation and accommodation occur through reflection and abstraction, as a result of cognitive conflict generated during one's interaction with the external environment. Radical constructivists believe that the individual's environment, including social processes, plays an important role in learning; however, they view learning as primarily an individual cognitive activity.

The sociological perspective, on the other hand, focuses on learning as participation in social processes, with individual cognitive activities contributing to the development of the social. Theorists operating from a social perspective, sometimes termed social constructivists or social constructionists, are similar to the radical constructivists in that they too reject the transmission or banking model of knowledge development. Theorists who view learning as primarily social, however, give 
priority to social and cultural processes in learning over individual cognitive activity. Those who follow the Vygotskian and activity theory tradition, for instance, consider learning to be "located in co-participation in cultural practices" [17] rather than located primarily within the cognizing individual. For these theorists, "the central concern is to delineate the social and cultural basis of personal experience" [17] in an effort to explain "how participation in social interactions and culturally organized activities influences psychological development" [17].

Just as constructivist theories of learning have been criticized for treating knowledge as exclusively psychological, theorists who view learning as a social process have been criticized for describing knowledge in social terms and not attending to the psychological side of students' constructive activities. The theoretical perspective on knowledge development that underlies this study represents an attempt to coordinate the psychological and social perspectives. This "emergent perspective" [22] does not give preeminence to either perspective, but instead asserts the usefulness of each for understanding how students come to know.

The emergent perspective holds that individual constructive activities and classroom social processes are reflexive and mutually constraining. On one hand, the emergent perspective goes beyond exclusively psychological approaches by viewing students' mathematical activity as being necessarily socially situated. Therefore, the products of students' mathematical development - increasingly sophisticated ways of reasoning - are seen to be related to their participation in particular communities of practice such as those constituted by the teacher and the students in the classroom. On the other hand, the emergent perspective questions the subordination of psychological processes to social processes and attributes a central role to analyses of individual students' mathematical activity [23].

In terms of research on students' mathematical development, proponents of the emergent perspective assert the usefulness of holding either the psychological or social as primary and then coordinating analysis between the two. But, this study does not consider students' mathematical development directly. Rather, the researchers consider teachers' efforts to engage students in certain kinds of classroom discourse.

Because the emergent perspective suggests that research on knowledge development must include attention to both the psychological and the social, teachers, attempting to support and promote knowledge development, must also concern themselves with both of these aspects. Building upon the emergent perspective, a view of the teacher's role that includes both the psychological and the social, has been developed [6], and it is upon his view of teaching that the researchers base the analysis of facilitating discourse.

In building his model of teaching, Simon [6] attempted to answer the question "If we give up showing and telling as the teacher's principal means for promoting students' mathematical development, what do we have to replace them?" He suggested two activities in which teachers can engage: posing problems and facilitating discourse. When teachers choose problems to pose they may be thought of as taking a cognitive view of the learning process, and when they attempt to facilitate classroom discourse they may be thought of as taking a social view [19]. Choosing problems to pose can be thought of as an attempt to influence the growth of cognitive structures by intentionally promoting and supporting accommodation and assimilation [6]. From the perspective of assimilation, the teacher focuses on what tasks might be undertaken successfully (but not trivially), given her model of the students' schemes. From the perspective of accommodation, the teacher focuses on what tasks might challenge the limitations of current schemes. The teacher's challenge is to identify student tasks that result in an appropriate balance between assimilation and accommodation. In addition, teachers can promote the cognitive activities of reflection and abstraction by choosing tasks that encourage students to reflect on their ways of thinking and make generalizations. The teacher as problem poser also contributes to students' views about the nature of mathematical activity. For example, problems can be posed in ways that engage students in searching for patterns, developing hypotheses, and justifying conclusions.

In choosing contextual problems used in this study, the researchers were influenced by the notion of level of cognitive demand. Problems with a low level of cognitive (lower order thinking) demand require only that students perform an algorithm by rote, whereas high-level tasks (higher order thinking) require pattern finding, generalizing, and making connections. If students are to engage in justifying their ideas and arguing among ideas, then it is reasonable to believe that high-level tasks have the potential to support discourse in ways that low-level tasks do not. Thus, there is an obvious relationship between teachers' efforts to pose problems that influence cognitive processes and teachers' efforts to influence social processes.

Teacher actions during discussions can be characterized as "the product of subtle improvisation in response to the dynamics and substance of student discussion." [24] These researchers suggest that orchestrating discussions requires a continuous analysis of (a) the value of the mathematics under discussion in relation to students, (b) the direction of the discussion and the degree of momentum, and (c) the social and emotional tone. Teachers' responses to each of these considerations influence students' views of mathematics and of the learning processes.

Interventions during group work can be at the individual level (e.g., teacher has a one-on-one conversation with one member of a group), the small group level (e.g., teacher has a conversation with one of the student groups in the class), and whole class level (e.g., halting group work to bring the whole class together); each of these types of interventions can help answer questions that many groups have, clarify the tasks, and reduce confusion to promote students' thinking [25]. Students benefit when teachers' intervention during group work can focus on both the dynamics of group functioning (process-help interventions) and the mathematical content (product-help interventions) [26]. In accordance with these research results, we created a lesson plan that was expected to help the teacher in helping students either as process-help interventions or product-help interventions. 
Simon's conception of teaching as posing problems and facilitating discourse was consistent with the researchers' desire to create classrooms similar to the "inquiry mathematics classrooms" [2]. Inquiry classrooms are places where students explore problems, make and test conjectures, explain and justify their ideas, and attempt to make sense of and evaluate the ideas of others. Students spend time in small groups exploring and discussing contextual problems, and in large groups contributing their ideas, and debating and building upon the ideas of other students and the teacher. Teachers engaged in inquiry-based instruction emphasize understanding and making connections among ideas. The teacher did not explain a set of rules to be followed, instead she engaged students in developing methods for solving problems. In inquiry-based classrooms, mathematical knowledge is determined by the ability to engage with the problem solving process, explain and justify ideas, and discuss and evaluate the ideas of others. Mathematical truth is no longer the sole possession of the teacher, rather it is the joint construction of the teacher and the students.[2]. Classroom discussions may be viewed as learning activities with both content-and process-related goals. Teachers make decisions about the appropriate placement and content of discussion based on their hypotheses of the process of learning and in response to their interactions with students.

\section{MEthodS}

This study is qualitative in nature, aims to investigate the factors that contribute to the facilitation of classroom discussion to promote students' understanding. The method to collect the data is that of 'teaching experiment' which was developed by Cobb, [8] in specific context in the classroom. For a period of three months, the researcher observed mathematics instructions to a grade five class which consisted of twenty-one students. The school is a laboratory school situated in the campus of Universitas Negeri Surabaya. Although the class teacher taught the lessons, the researcher played an active role in preparing the lesson plans, helping the teacher in clarifying any confusion that arose in small-group and whole class discussions, helping the teacher and making observations during the whole lessons. Each lesson period lasted seventy to one hundred and five minutes. All phases of the lesson were videotaped using three cameras. One camera focused on the teacher, one camera focused on a group of students, while another camera focused on the whole classroom. This three-camera technique rendered this classroom data set an excellent resource for studying how was the teaching and learning process going on, and what were the teacher activities and the students activities in classroom discussion in order for the students to construct the learning materials.

When the students were working in small groups, audio tape recorders were also used to record the discussion in some selected groups. Follow-up interviews were held with students who had shown some evidence of reaching new understandings over the course of a lesson. The researchers prepared a lesson plan on the materials of statistics which consisted of reading the data presented in tabular form, writing the meaning of mode, median and mean, and determining the mode, median and mean of a group of data, as well as solving contextual problems related to mode, median and mean. The researchers also provided student worksheets, and administered assessments of student learning.

Then, the researchers conducted a qualitative analysis which consists of 3 (three) stages which are data reduction, data presentation, and conclusion [25]. Data reduction is a form of analysis that sharpens, classifies, directs, discards the unnecessary, and organizes the data in such a way that the final conclusion can be drawn. One of the ways used by researchers in data reduction is coding the words or phrases in order to describe and identify meaning or data patterns. The next step is presenting the data. The data that can be obtained by the researcher are presented in the form of words or sentences. The presentation of the data is done with the transcript of the interview, which is a detailed and complete description of what is seen and heard through the recording. The third step in analyzing the data is to draw conclusion. The conclusion of the research is drawn continuously while in the field, but new conclusions can be obtained when all data have been collected and all processes of data analysis have been done. Thereafter the researchers identified constituent parts of the lesson, starting with major events and moving progressively to the actions of individuals. A comparative analysis of lessons was also undertaken.

\section{RESUlT AND DisCUSSION}

In this study the researchers observed the teacher activities in facilitating classroom discussion which consist of small group discussion and whole-class discussion to promote students' understanding. The teacher conducted mathematics instructions using prepared lesson plans. She conducted learning processes that make classroom discussion more manageable by applying the teacher's role. [27], [28]. It is based on reported research results that if students are left to their own devices, they will not necessarily engage in highquality math-talk. Consequently, the classroom discussion should be well-managed by the teacher.

We have special reasons why in this study we use statistical materials for our research. First, the material of statistics is one of the mathematics contents in Curriculum 2013 to be taught in the even semester. Then, statistical knowledge is indispensable not only for individuals to learn the content, but it also has social impact. Therefore, the statistical content functions as either a scientific knowledge or as a practice of scientific production. It can be seen in the curriculum 2013 that the contents of statistical materials are primarily collect, organize, read and interpret data or information. Thus, the purpose of learning statistics is giving opportunities to the students in constructing procedures to collect, organize, communicate data using tables, graphs and representations that are often seen in their daily lives, as well as to interpret statistical data using some statistical measures, such as mean, median and mode. [5].

The following is an overview of the teaching and learning process at the classroom. The teacher began the lesson by conducting an introduction, i.e. motivating the 
students, stating the purpose of learning the materials, and relating the materials with the ones they have learned before (i.e. apperception). The teacher motivated the students by conveying the usefulness of statistics in daily life, i.e. by providing contextual problems associated with the presentation of data in the form of tables and diagrams. In addition to drawing on their knowledge of mathematical content, the teacher must also bring to classroom discussions an understanding of their students' prior knowledge and experiences. This is what we usually called as 'apperception.' In the second step of instruction, the teacher assigned tasks in the form of worksheet that required students to work together to do mathematical activities, and to develop joint solutions and problem-solving strategies.

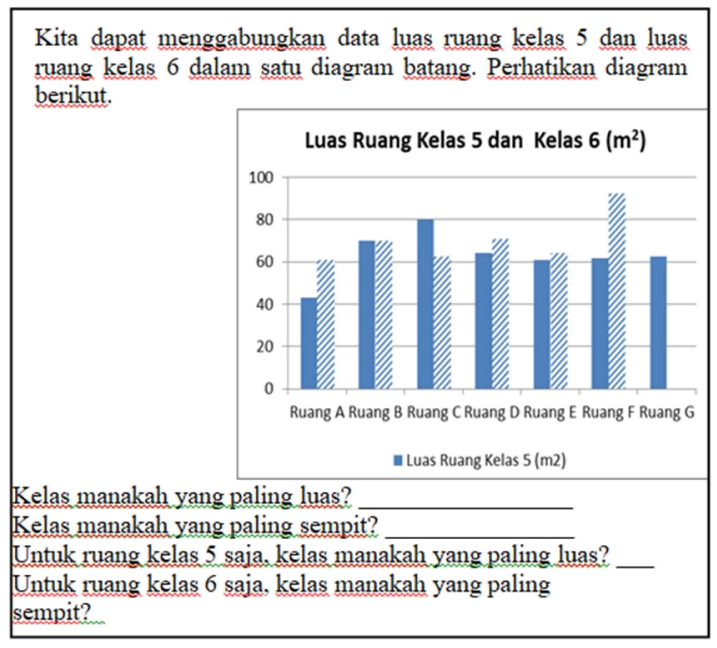

Fig. 1. A part of mathematical problems that should be solved by the students in group work.

As can be seen in Figure 1, the worksheet contains mathematical tasks that are appropriately challenging and enhance students' learning. The mathematical tasks investigate important mathematical ideas and relevance for students. It needs students to read and analyze the bar diagram, and then answer the questions provided in the worksheet. In addition, the mathematical activities and the problems posed encourage investigation, promote reasoning, and require students to provide justifications for their thinking. Ultimately, the mathematical tasks in the worksheet are worthy of student discussion and emphasize important mathematical concepts. The student worksheets also consist of a multilevel task, and were created by considering that scales of group work learning tasks must be set at an appropriate level to encourage group working. The tasks were not set at too low or too high of students' cognitive level, because it would discourage student participation. [28]. In other words, the tasks were in the students' Zone of Proximal Development. [29].

In the third step, the teacher divided the students into five small groups whose members were heterogeneous. This is parallel to the findings of studies by Galton and his colleagues which suggest that students are more likely to succeed in undertaking cognitive tasks when they work in pairs or small groups. The small groups consisted of 4 (four) or 5 (five) students which was in line with the recommended size for the pursuit of cooperative and collaborative tasks, with the tasks involving enrichment and incremental learning. Then, after small-group work, the teacher also implemented whole class discussion that was expected to provide a context for the wider transmission of knowledge.

However, to gain effectiveness of group working, the students were encouraged to establish positive relationships between group members that allow for sensitivity to others, trust of others and effective communication. It is because learning processes related to cognitive development (either new knowledge or application of knowledge) will be enhanced by effective social communication and support. The figures below illustrate the situation of mathematics learning at Mrs. Mar's classroom.

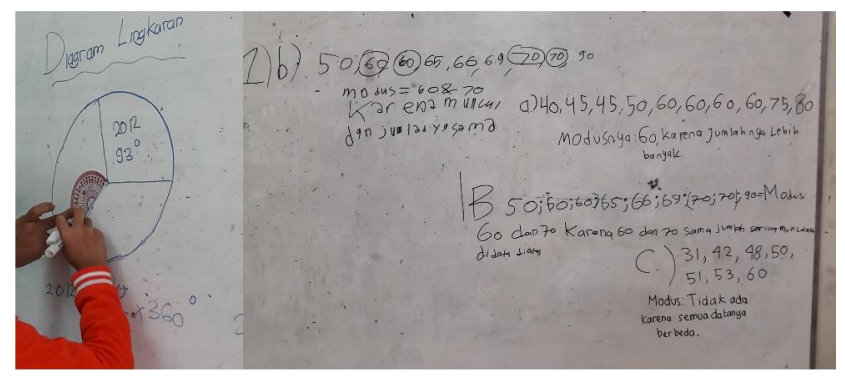

Figure 2 \& 3 Results of students' discussion were written on the whiteboard, and then all members of the group presented their work in front of the class.

As can be seen in Figure 2, a female student accompanied by other members of the group draw a pie diagram on the whiteboard to represent the data they were given in the worksheet. The mathematical tasks investigate important mathematical ideas and relevance for students, such as the explicit notion of pie diagram, the types of data, the concept of mode in ungrouped data. Besides, the students had grasped the concept of mode as can be seen in Figure 3. They have realized that there are three possibilities of the existence of modus in ungrouped data: one mode, two mode or no mode. In other words, it can be said that the mathematical activities and the problems posed encourage investigation, promote reasoning, and require students to provide justifications for their thinking. Ultimately, the mathematical tasks in the worksheet are worthy of students' work in group and emphasize important mathematical concepts.

We have a specific reason why we use the material of statistics in this study. Statistical knowledge is indispensable not only for individuals to learn the content, but it also has social impact. Therefore, the material of statistics functions as either a scientific knowledge or as a practice of scientific production. There are four steps of solving problem that are used as a basis to analyze the pattern of interaction in this study, namely, understanding the contextual problem, solving the problem individually, comparing and discussing answers, as well as drawing a conclusion or writing a summary. 
In terms of the strategies used by the teacher to facilitate discussion, it can be summarized as the followings.

(1) Using "Discourse-Enhancing" Strategies

Suggestions for improving or facilitating classroom discussions include establishing participant frameworks, using strategies for engaging students in discussion, and providing students with more time to wrestle with a problem or idea. Knowledge of recommendations such as these is important both to discussion facilitators and to researchers examining and characterizing the process of facilitating discussion.

One method of incorporating students' ideas into classroom discussions is to reconstruct students' solution methods or paraphrase students' responses. Often termed "revoicing", this strategy can serve the potentially beneficial purpose of helping to establish participant frameworks [19]. By reconstructing or paraphrasing students' contributions to classroom discourse, teachers can frame discussions and position students' ideas within these frames. The following dialogs are some examples of revoicing used by the teacher.

Teacher: Who can describe how should we begin to solve this problem?

Annisa: I see the bar diagram and read it.

Teacher: So, Annisa says to begin by looking at the bar diagram and getting information given in the

Diagram. Does anyone begin a different

way?

The first word in the teacher's response, "so", is a marker for a warranted inference. The word "so" indicates that the speaker (teacher) intends to make an inference that she believes is warranted based on the remarks of the previous speaker (student). Next, the teacher engages in termed animation [30], that is, the teacher brings the student to life by using the words "Annisa says". Goffman called "says" a laminator verb because it is used to link the subject of the sentence (Annisa) with some proposition (a method for beginning to solve the problem in question) [19]. Animating Annisa in this way gives her a particular status or position within the discussion - Annisa's personal method for beginning the problem becomes a suggestion for the entire class. In addition to animating and positioning students within a discussion, paraphrasing students' words is one way teachers can model the use of more formal mathematical language. It has been argued that revoicing may be useful for (a) positioning students and their propositions within a participant framework, (b) reformulating students' ideas in more official language while still crediting them verbally, and (c) strengthening a weak voice that might otherwise be overlooked.[30].

\section{(2) Engaging Students in Discussion}

Discourse strategies for students, coupled with establishing norms and expectations for behavior, were useful for altering patterns of discourse during classroom discussions. Teachers can encourage students to explain, build, and go beyond [4] by asking questions such as "Can you explain why?", "So, what do people think about that?", or "Do you agree or disagree with_'s idea?" Besides, in this study, the teacher encouraged students to respond to and question each other's ideas by using sentences such, "Who can respond to__s suggestion?" or "That is an excellent question. Anybody else want to take a shot at it?"
Overall, the strategies used by the teacher to encourage students to participate in discussions, involve: (a) identify students with good ideas to share and give them a "heads up" prior to discussion, (b) use wait time before and after students speak, (c) try not to comment after each students' response, instead simply pause and wait for someone else to talk, (d) avoid accepting only one response to a question.

\section{(3) Providing Think Time}

Students may need time to wrestle with a new idea or revisit an old one before they are prepared to share their ideas publicly. Teachers can use small group or individual work time to listen to how students are thinking. Understanding students' thinking gives teachers an opportunity to better facilitate discussion when the whole-class reconvenes. If students are not given time to wrestle with ideas that arise in discussion, teachers may be tempted to revert to more directive methods such as funneling or cued elicitation [19].

When discussions are viewed as opportunities to share ideas and move mathematical thinking forward, rather than times for wrapping up lessons or explaining to students the meanings behind their investigations, teachers may be more comfortable with not correcting faulty thinking. Although teachers can push students to attempt to reach consensus, consensus may not be attainable at a given point in time. By sending students back to their small groups for further investigation, teachers can help students move toward consensus without short-circuiting their inquiries.

\section{(4) Engaging Students with Tasks}

When the researchers engaged in planning, we frequently reflected on students' understandings and our goals for student learning. We then prepared a task or a series of tasks to implement in the classroom. Next, we considered how best to utilize discourse, both oral and written, to further students' mathematical development.

The researchers' goals for student learning included understanding the meaning of data, mode, median, mean and read a given diagram as well as represent data into a suitable diagram or graph. Considering the relationship between classroom discussion and mathematical task was an important initial piece of the process of facilitating discussion for us. We also found ourselves concerned with (a) providing students with sufficient opportunities to develop opinions about the mathematics at hand prior to discussion and (b) engaging students with tasks in such a way that they need to do the tasks with the members of their group. Students' ideas were tentative and, almost all students were willing to share their thoughts, and they engaged in justifying their own ideas or evaluating the ideas of others.

Facilitating classroom discourse in general, and wholeclass discussion in particular, was a central component of teaching mathematics for us. As we planned for and reflected on instruction, we focused repeatedly on students' engagement with tasks and how this engagement related to discussion. We kept four considerations in mind: (a) when and how to best incorporate whole-class discussions to further students' mathematical understanding, (b) how to engage students with tasks in ways that would help them develop ideas and opinions, (c) how best to manage differences in students' understandings 
so that all students might benefit from whole-class discussions. The process of facilitating discussion involved consideration of them.

\section{a)}

(5) Engaging Students in Sharing and Listening

The researchers put a considerable amount of effort into trying to bring students' ideas and ways of thinking to the forefront of discussion and encouraging students to listen to each other. The work in this area falls into three categories: (a) structuring space, (b) encourage talk and presenting students' ideas, and (c) motivating listening. The first category relates to both sharing and listening, the second primarily to sharing and the third to listening.

\section{(6) Encouraging Talk and Presenting Students' Ideas}

Traditionally, facilitating discussion has been synonymous with "leading" discussion and has referred to what a teacher did or might do during a given discussion [19]. The researchers have conceptualized the process of facilitating discussion more broadly to include teacher activities that relate directly to discussion but occur before or after it. Therefore, we examined data not only from discussions themselves, but also from planning and reflective activities, in order to identify a wider range of discussion-related issues embedded in various parts of the teaching process.

In addition to analyzing the ways in which students engage in talking about mathematics, teachers can ask students directly about the usefulness of discussions. When students write about the ideas they shared, the questions they asked or responded to, and the understandings they developed, they consider both how they contributed to and how they benefited from the discussion. In addition, students' writing provides teachers with evidence of the level of involvement of students, regardless of whether or not they spoke during the discussion.

\section{CONCLUSION}

This study is a qualitative case-study aims to examine the process of facilitating discussion in elementary mathematics classrooms to promote students' understanding. The researchers positioned as an insider or active participant who engaged in the mathematics instruction being studied. This position gives the researchers unique insight into the process of facilitating discussion, but required careful, disciplined methods of data gathering and analysis.

In the new curriculum (K-13), learning mathematics is viewed as a social endeavor in which mathematics classroom functions as a community where thinking, talking, agreeing, and disagreeing are encouraged. It is parallel to the recommendation that encourages educators to prepare the students with the skills needed to live in the 21 st century which are called as 'Four Cs' (creativity, critical thinking skills, communication and collaboration). Using classroom discussions as a tool for learning mathematics requires significant time and effort on the part of teachers. Established patterns of interaction must be altered and strategies for encouraging students to listen and respond to each other must be learned. Analysis of our experience in planning, implementing, and reflecting on discussions suggests that strategies used by the teacher to facilitate classroom discussion involve: (a) engaging students with tasks, (b) engaging students in sharing and listening, (c) engaging students in questioning and clarifying, and (d) engaging students in agreeing and disagreeing. Engaging students with tasks refers to the efforts to engage students in thinking about particular mathematical problems or tasks, while sharing and listening, questioning and clarifying, and agreeing and disagreeing refer to issues that arose for us during the discussions themselves, as well as during planning and reflecting. The four features of the process are highly interdependent, and that concern with one aspect generally involved concern with the other three. For example, concern with whether or not students' engaged in agreeing or disagreeing with each other was related to concerns over students' willingness to listen to each other, and concern for students' behaviors during classroom discussions was related to concerns about engagement with tasks prior to discussion. Decisions about direction, tone, and mathematical value must be made during discussions and some method must be used to judge the quality of discussions.

In order to help students summarize and understand their thinking as well as the thinking of others, the teacher provide opportunities for students to "turn and talk" about their solutions. Teacher should also facilitate the sharing of strategies with all students in the classroom to promote student reflection on the different strategies. This gives students practice in constructing arguments, providing justifications, and critiquing the thinking of others. In summary, how successfully a teacher facilitates collaborative work will drives how mathematically rigorous the work is for students. Equally important is that students know how to listen to the thinking of others, and pose questions, as a way of deepening their mathematical understanding.

\section{ACKNOWLEDGMENT}

This research was a part of a comprehensive research for the author's dissertation submitted to Pascasarjana Universitas Negeri Malang. The first author is thankful to Prof. Dr. Cholis Sa'dijah, M.Pd., M.A., Dr. Abdur Rahman As'ari, M.Pd., M.A., and Dr. Makbul Muksar, M.Si. as Dissertation Supervisors. The author is also thankful to Prof. Dr. Suyono, M.Pd. as Dean of the Faculty of Mathematics and Natural Sciences, Universitas Negeri Surabaya; Prof. Dr. Madlazim, M.Si. as Vice Dean I of the Faculty of Mathematics and Natural Sciences; Dr. Wasis, M.Si. as Vice Dean II of the Faculty of Mathematics and Natural Sciences; as well as to Dr. Ismail, M.Pd. as Head of Department of Mathematics, Universitas Negeri Surabaya, for providing the necessary facilities and supports for the preparation of the paper.

\section{REFERENCES}

[1] J. Boaler, "The development of disciplinary relationships: Knowledge practice and identity in mathematics classrooms", For the Learning of Mathematics, vol. 22 
pp. $42-47,2002$.

[2] P. Cobb, T. Wood, E. Yackela and B. McNeal, "Characteristics of classroom mathematics traditions: An interactional analysis". Am. Educ. Res. J. vol. 29, pp 573-604, 1992.

[3] J. Hodgen, "Formative assessment: Tools for transforming school mathematics towards a dialogic practice? In D. Pitta-Pantazi \& G. Philippou Eds. Fifth Congress of the European Society for Research in Mathematics Education. Larnaca Cyprus: University of Cyprus, pp. 1886 - 1895, 2007.

[4] M.G. Sherin, "A balancing act: Developing a discourse community in a mathematics classroom". J. of Math. Teach. Educ. vol. 5, pp 205-233, 2002.

[5] R. Setianingsih, C. Sa'dijah, A.R. As'ari and M. Muksar, Investigating fifth-grade students' construction of mathematical knowledge through classroom discussion. Math. Educ. vol. 12, pp. 383-396, 2017.

[6] M. Simon, "Developing new models of mathematics teaching: An imperative for research on mathematics teacher development". In E. Fennema \& B. S. Nelson Eds. Mathematics teacher in transition. Mahwah, NJ: Lawrence Erlbaum, pp. 55-86, 1997.

[7] R. Setianingsih, "Patterns of interactions at grade 5 classroom in learning the topic of statistics viewed from cognitive load theory". J. of Phys. Conf. Series, vol. 953. $012212,2017$.

[8] P. Cobb, Conducting teaching experiments in collaboration with teachers. In E. Kelly \& R. Lesh Eds. Handbook of research design in mathematics and science education. New Jersey and London: Lawrence Erlbaum Associates, 2000, pp. 307-333.

[9] K. Sawyer, "Creative teaching: Collaborative discussion as disciplined improvisation. Educ. Researcher, vol. 332, pp.12-20, 2004.

[10] J. Boaler, "Promoting 'relational equity' and high mathematics achievement through an innovative mixed ability approach. British Educ. Res. J., vol. 34. pp 167194, 2008.

[11] E.G. Cohen, Designing group work: Strategies for the heterogeneous classroom. New York, NY: Teachers College Press, 1994.

[12] R.E. Slavin, Cooperative learning. Baltimore, MD: Center for Social Organization of Schools, John Hopkins University, 1980, pp. 315-342.

[13] E. Yackel, P. Cobb, and T. Wood, "Small-group interactions as a source of learning opportunities in second-grade mathematics". J. Res. Math. Educ. vol. 22, 1991.

[14] L. Martin, J. Towers and S. Pirie, "Collective mathematical understanding as improvisation". Math. Thinking and Learning, vol. 82, pp. 149-183, 2006.

[15] L. Martin and J. Towers, Improvisational etiquette and the growth of collective mathematical understanding. In T. Lamberg \& L. R. Wiest Eds. Proc. of the 29th Annual Meeting of the North American Chapter of the International Group for the Psychology of Mathematics
Education. Stateline Lake Tahoe, NV: University of Nevada Reno, 2007, pp. 201 - 208.

[16] T. Dooley. Construction of knowledge by primary pupils: The role of whole-class interaction. In D. PittaPantazi \& G. Philippou Eds. Fifth Cong. of the Eur. Soc. for Res. in Math. Educ. Larnaca, Cyprus: University of Cyprus, 2007, pp. 1658 - 1667.

[17] P. Cobb and H. Bauersfeld, Introduction: The coordination of psychological and sociological perspectives in mathematics education. In P. Cobb \& H. Bauersfeld Eds. The emergence of mathematical meaning. Hillsdale, NJ: Lawrence Erlbaum, 1995, pp. 116.

[18] M. Lampert, "When the problem is not the question and the solution is not the answer: Mathematical knowing and teaching". Am. Educ. Res. vol. 27, pp. 29-63, 1990.

[19] R.H. McGraw, Facilitating whole-class discussion in secondary mathematics classrooms. Doctoral Dissertation. Indiana University. Retrieved from http://math.arizona.edu/ rmcgraw/RMcGrawThesis.pdf., 2002.

[20] P. Freire, Pedagogy of the oppressed. New York: The Seabury Press, 1970.

[21] E. Von Glasersfeld, A constructivist approach to teaching. In L. P. Steffe \& J. Gale Eds. Constructivism in education. Hillsdale, NJ: Lawrence Erlbaum. 1995. pp. 3-15.

[22] P. Cobb, "Continuing the conversation: A response to Smith". Educ. Researcher, vol. 245, pp. 25-27, 1995.

[23] P. Cobb, Conducting teaching experiments in collaboration with teachers. In A.E. Kelly \& R.A. Lesh Eds. Research design in mathematics and science education. Mahwah, NJ: Lawrence Erlbaum, 2000, pp. 307-333.

[24] D. Chazan and D. Ball, "Beyond being told not to tell". For the Learning of Mathematics, vol. 19, pp. 2-10, 1999.

[25] M. Ding, X. Li, D. Piccolo and G. Kulm, "Teaching interventions in cooperative learning mathematics classes, J. Educ. Res. vol. 100, pp.162-175, 2007.

[26] R. Dekker and M. Elshout-Mohr, Teacher interventions aimed at mathematical level raising during collaborative learning, Educational Studies in Mathematics, vol. 56, pp. 39-65, 2004.

[27] C.D. Bruce, Student interaction in the Math Classroom: Stealing Ideas or Building Understanding. What Works? Research Monograph \# 1 Research into Practice. Ontario: the Literacy and Numeracy Secretariat and the Ontario Association of Deans of Education, 2007.

[28] S.H. Chapin, C. O'Connor and N.C. Anderson, Classroom discussions: Using math talk in elementary classrooms, Math Solutions 11, Retrieved from http://www.mathsolutions.com/ documents/0-941355-535_L.pdf,_2003.

[29] L. Vygotsky, Mind in Society: The development of higher psychological processes. Cambridge, MA: Harvard University Press, 1978. 
[30] I. Goffman, Forms of talk, Philadelphia: University of

Pennsylvania Press, 1981. 